\title{
Technical Vocational Education Training Institute Curriculum Development in Ethiopia
}

\author{
Lemecha Geleto \\ College of Education and Behavioral Studies, Addis Ababa University, Ethiopia \\ lemechageleto@yahoo.com
}

\begin{abstract}
Ethiopian TVET curriculum development process follows similar procedures with different competency based TVET curriculum development processes in some countries. Ethiopia mainly adopted its current TVET curriculum experiences from countries such as Australia and Philippines. Depending on the trends of these countries, the new Ethiopian TVET strategy has decentralized the preparation of curricular materials to the institutions that deliver training. The problem may limit the current competency based TVET curriculum in Ethiopia is lack of knowledge and experience to develop the curriculum at the local level in this decentralized responsibility to develop the curriculum at TVET institutions. In addition to the problem of decentralization, the continuous change made in the occupational standards is another challenge in the effective implementation of the reformed TVET approach. While TVET institutions have set themselves and started to provide training in certain occupational standards disseminated, the Ministry of Education in the mean time updates or replaces those occupational standards with the new ones. This has created resource wastage and grievance at institutions, management, instructors and students.
\end{abstract}

Keywords: Competency; occupational standards; decentralized TVET curriculum; competency based curriculum, recognition of prior learning

\section{Introduction}

The role of TVET in human resource development and the consequent growth and prosperity of society is an established fact. This is because TVET furnishes skills required to improve productivity, raise income levels and improve access to employment opportunities for people. It does this by playing three major roles: meeting the human power needs of society; raising the employment opportunity of citizens thereby improving their livelihood; and motivating citizens for further education and training (Schokland Program on TVET, 2012). They also define TVET as education and training activity that is mainly provided to lead participants to acquire skills, knowledge, and understanding necessary for employment in a particular occupation or group of occupations. Rauner and Maclean (2008) also stated that vocational education is considered a key factor for improving or maintaining the competitiveness of enterprises and national economies. Historically, TVET had long existed as indigenous practices such as work of artisans, blacksmiths, potters, weavers, etc. in Ethiopia. Due to the bad attitudes towards these skills by the society, TVET got less attention and slow development in Ethiopian education history. For instance, Teklehaimanot (2002, as cited in Learn4Work, Schokland Program on TVET, 2012) stated that the extent of misconception and prejudice goes to the worst level whereby artisans and blacksmiths have been considered not only as low caste people but as sinners in the social life of the society as well. Even in the modern times, as a result of this misconception of TVET by society and categorization of TVET learners as low achievers by society, TVET enrolment in Ethiopia existed among the lowest in sub-Saharan African countries (King, 1985, as cited in Schokland Program on TVET, 2012). However, as of not more than three decades, Ethiopia made a big effort in changing this history of misconception toward TVET. Particularly, the year 1994 can be taken as the turning point in this regard. This was the time whereby the newly assumed Transitional Government of Ethiopia (TGE), which replaced the Derg regime, has introduced the Education and Training Policy in 1994 that gave a due emphasis for TVET and the involvement of the private sector in TVET delivery in particular and the need for overall partnership in general (TGE, 1994, as cited in Learn4Work, Schokland Program on TVET, 2012).

Regarding TVET curriculum, prior to 1994 and even between 1994 and 2006, before the launch of New TVET Strategy, TVET had been curriculum based and input based. According to the interview with TVET agency officers (Hulualem, Mosisa, and Fitsum) and the brochure of the TVET agency, the pre-2006 TVET curriculum was characterized as 1) the occupations are determined by ministry of education, not by industry or labor market; 2) the training was depended on the curriculum, not on occupational standards; 3) the assessment of the quality of the training was depended on the completion of curriculum contents that was prepared by the 
Federal TVET agency rather than by the criteria set depending on the occupational standards derived from the existing industry; 4) the assessment mechanism depended only on teacher made training exams, not by the exams that are depended on the achievement of the competencies derived from the occupational standards and prepared by the experts that work in the industry concerned; 5) assessment was the direct assessment depended on teacher made formal training exam rather than considering the prior skills the trainees may have acquired informally outside the formal training; 6) The competence of the trainee was judged depending on the completion of the training year and the length of the time spent on training not depended on the performance of the trainee at work that is measured by center of competence assessment; 7) the occupations/programs that were delivered to 10+1 to 10+3 included only those who completed grade 10 and had adequate national exam results; they didn't consider those who dropped out of school prior to grade 10. The new TVET strategy chooses from the level 1 competencies and gives short training for those who drop out of school at the different grade levels; 8) the old trend trains and gives certificate only; the end of the work of the new training is up to enabling the trainees to pass the center of ${ }^{1}$ competence exam and harmonizing them with work; 9) the former recognizes competence by the school completion certificate; there was no center of competence assessment outside the training institute; 10) unlike the former, the latter didn't limit its training to formal training rather it invites and participates governmental and nongovernmental organizations in the process of training trainees informally and non-formally; 11) previously, there was no habit of supporting and encouraging small micro-enterprise organizations, but currently, the major emphasis is given to supporting and developing these organizations. Objectives of this paper are to:

- Describe Competency Based Curriculum Development and its process in Ethiopian TVET;

- Discuss the application of modularization in terms of the world and in terms of Ethiopian TVET and

- Examine Ethiopian TVET against the Theory and Practice of Competency Based Curriculum

\section{Literature Review}

Competency Based Curriculum Development: The use of the competence concept has old roots in the theory and practice of curriculum field that can be traced back to the competency movement started in the United States in 1960s-1970s and spread worldwide. Some studies, identify even earlier links of the concept to the development of mastery learning models in the U.S. during the 1920s and suggest that the competence based approaches were concerned with formative vocational education and training, and reflected instructional design informed by psychology: namely, the work of Skinner, hence the association with behaviorism (Kate, 2014, cited by soare, 2015). This way, Soare said, the word competency began to be used in association with this model of instruction and learning, and a number of concepts associated with modern competency based learning (CBL) came out together with the epistemological shift from input to outcomes. Wesselink et al. (2010) also states that the origin of the idea of working with competencies in educational contexts lies in the US. They say that in the 1960s it was labeled 'performance-based teacher education' and characterized by its detailed analyses of the behavioral aspects of professional tasks. Barnett (1994, cited in Wesselink et al., 2010) concluded that competencies described in this more behaviouristic way cannot provide guidelines for a curriculum because of the level of detail. As a result, CBE did not become a success in the US because of this emphasis on detail. Today, in Europe, a more holistic approach to competence is being used (Eraut 1994, Biemans et al., 2004, cited in Wesselink et al., 2010): a competence is always seen in the context in which it will be used and includes a functional component, a personal or behavioral component, a cognitive component, and an ethical component (Cheetham and Chivers 1996, cited in Wesselink et al., 2010).

Parry (1998, cited in Soare, 2015) defines the competence as a cluster of related knowledge, attitudes and ${ }^{2}$ skills that fulfill several criteria: a) affects a major part of one's job, b) correlates with performance on the job, c) can be measured against accepted standards, and d) can be improved via training development. The other definer defined competency as "a knowledge, skill, or attitude that enables one to effectively perform the activities of a given occupation or function to the standards expected in employment" (International Board of Standards for Training and Performance Instruction, 2005, cited in Chyung, Stepich \& Cox, 2006). Generally, these authors stated competency includes both means and an end. The means are knowledge, skills, or abilities and the end is to effectively perform the activities of a given occupation or function to the 
standards expected in employment. They also assert that the term competency loses its true meaning if the end is ignored. In addition, Rauner and Maclean (2008) stated that the concept of competence is used in two different ways: first, as a capacity or ability, and second, as a province of responsibility or field of authority for example, the authority to make decisions. The first usage corresponds to the concept of "competence" or "competences" used the field of vocational education: here, an individual is considered "competent" when possessing the ability to do something specific.

The 'competence-based approach' or 'competence-based education and training' (CBET) can only be understood as a curriculum strategy which aims at an encoding of intended abilities and facilitating dispositions. Attempts are then made to achieve these codified elements of learning as goals of work- related, experience-related, and school learning processes and, if applicable, the elements are then evaluated and certified as the results of such processes. In the final analysis, they are standards which, as individual curricular elements and predetermined outcomes, are derived from existing occupational profiles and assigned to various (primary) units of learning (units, modules) which, in turn, are to be related to complex operational functions and tasks. The responsibility for the success of the learning process lies predominantly with the learner, and the learning process itself is subordinate to the successful learning outcome. For the educational standards, the content-related specifications are, at the most, only of secondary importance (Rauner and Maclean, 2008). Grant et al. (1979, as cited in Soare,2015) define competency based education as a form of education that derives the curriculum from an analysis of a prospective or actual role in contemporary society and that attempts to certify student progress on the basis of demonstrated performance in some or all aspects of that role. These authors, (Rauner and Maclean, 2008), discussed the two supranational level perspectives developed in the North American and European context as traditionally proved to be of special significance for designing the learning process.

North American Perspectives: Rauner and Maclean (2008) stated that a major theme of debates on the international scale has to do with the changed demands on employees in the context of a globalized, comprehensive labor market which involves increased risks of friction due to intensified adaptation problems and, as a consequence, can produce considerable mismatches on the labor market. In this sense, the authors say that the issue of knowledge distribution, as directed by the educational and training process, is also fore grounded internationally. These authors discussed the curricular solution for this international risk of friction here under. They stated that the $0^{*}$ NET content model designed by Mumford and Peterson in 1999 is perceived as a multi-perspective approach which is to provide the following qualification-related information (cf. Buch /Frieling, 2004, cited in Rauner and Maclean, 2008): Experience Requirements (Training); Worker Requirements (Basic Skills, Education, Cross-Functional Skills); Worker Characteristics (Abilities, Occupational Interests, Work Values, Work Styles); Occupational Characteristics ( Labor Market Information); Occupation-Specific Requirements (Work-related Knowledge, Skills, Tools, Equipment); Occupational Requirements (Generalized Work Activities, Organizational Context)

According to Rauner and Maclean (2008), another internationally influential approach to developing vocational curricula has become known by the label "DACUM" (Developing A Curriculum). The DACUM approach is intended to facilitate the analysis and description of needs and skill profiles. According to its express self-image, the following three "logical premises" are taken into consideration in this approach :(1) Expert workers are more capable of describing and defining their job reliably than anyone else. In so far, as they do their job in the context of normal employment, they can be called "expert workers"; (2) the most effective way to describe a job is to define areas of responsibility and the tasks and individual steps involved. But the worker behaviors accessible and the knowledge of such behaviors do not suffice. Expert workers are able to explain their knowledge and skills, i.e., to train others to be experts; the knowledge, skills, abilities, and attitudes required for the work are now regarded as variables ("enablers") of work successfully carried out. These authors also indicated that they, the three above listed, are so significant that considerable care is taken to appropriately identify them. They also show brief procedures of DACUM (Developing a Curriculum). They said, firstly, a group of five to twelve occupational practitioners forms the decisive source of information for the analysis of work processes. In two to three-day meetings under the guidance of a DACUM facilitator, this group develops a needs analysis or a DACUM chart listing tasks, general knowledge, abilities/skills, behaviors, tools, equipment, materials, as well as future developments. These lists represent the empirical basis for "competency-based education (CBE)" and for the "instructional development" based on CBE. The 
development of the profile is furthered by moderation techniques which take recourse to meta-planning techniques such as brainstorming, clustering, comparing, evaluating, etc. An open experiential exchange between the occupational practitioners is ensured by the facilitators, who take care that the major categories of analysis are used precisely and unambiguously.

European Perspectives and Approaches: the Concept and Development of Modularization: The authors state that in light of the European attempts at establishing control mechanisms of curricula during the last quarter of a century, it is obvious that all of these attempts were not aimed at designing students' educational careers in the traditional institutions of the (public) educational system, but, instead, were focused on external processes of knowledge production. Among such attempts, the following are especially noteworthy: i) the (formal) demand for lifelong learning, brought forward by the OECD and UNESCO during the 1970s and especially influential in Europe; ii) the emphasis on self-responsibility in the demand for a self-organized and self-regulated learning process in widely divergent general and specific contexts; iii) the frequently emphasized necessity of e-learning for more effective use of learning time and minimizing costs. In order to ensure freedom of movement within the European education and labor markets and the comparability of processes of knowledge production, these authors assert that debates on aspects of control mechanisms have centered on issues of standardization in their treatment of traditional educational institutions. Such debates have resulted in the (further) development of the following structures: a harmonization of degrees and the establishment of a credit system. At a formal level, the authors illustrate that, these control mechanisms facilitate interconnections between the following goals in VET: transparency, comparability, permeability, support for mobility, reevaluation of informal learning processes, individualization and rationalization of courses of study, creation of a basis of trust between educational providers and their clientele at home and abroad, and quality control.

Within the European context, curricular control mechanisms are put into practice in two main ways: pertaining to organizational and structural aspects, and, to a certain extent, content-related curricular control mechanisms: The structural control mechanisms focus on modularizations in nonacademic and, more recently, also in academic institutions of education and further education. The term modularization refers to widely divergent models of opening up courses of study and making them more flexible with respect to organizational, temporal, and content-related structures. These authors state that an example of modularized vocational education has been implemented in Great Britain with the system of National Vocational Qualification (NVQ). NVQ provides for the individual compilation of various partial certificates in a 'qualification portfolio' and facilitates access to employment already on the basis of partial certification. In the modularization model used in Denmark and the Netherlands, the degree also functions as the sum of the partial certificates obtained. But these are mandatory components assigned specifically to certain courses of training, and, in this sense, these models are more moderate variants of modularization. In structuring curricula by way of modularization, the main emphasis is on combining fundamental and supplementary building blocks of education and training and, thus, on their variability and flexibility with reference to temporal and content-related aspects. The basic variants of modularization currently under debate encompass the following three perspectives: the supplementation model develops from temporal sequencing; the fragmentation model develops from the combination of agency and certification; the differentiation model is more strongly oriented towards curricular considerations.

The variability of the control mechanisms is based on various traditions concerning curriculum development and its theoretical basis. German curriculum development in VET is based on a didactic curricular understanding which is fundamentally characterized by the selection and organization of subject-specific content and areas of learning. To put this way, whether learners are able to develop the required dispositions depends on the adequate selection and logical organization of content in the curriculum. Thus, this curricular perspective is both input and output-oriented. In contrast, the international approaches favor an explicit output orientation with their focus on the identification and certification of application-oriented abilities. Rauner and Maclean (2008) pointed out that with regard to the competencies to be developed, stress should be placed on the specific characteristics of the German concept of Kompetenz, which is noteworthy because of its goal-related perspective on the processes involved in VET, a perspective that aims at ability and competence for action in the sense of a specialized competence. At the same time, this ability to act and evaluate with reference to specific subject matter is indissolubly linked to a distinctive form of self- 
directedness and to a competence in societal and political issues. Competence development understood in this way aims at enlightenment and emancipation through the process of education. In contrast, they stated, the concept of competence in the international context is directed toward the simple characterization of desired behaviors and activities.

Curriculum Development Process in TVET: The next to DACUM, popular competency based curriculum development is the Systematic Curriculum and Instructional Development (SCID). Norton (1992) states that to provide structure for developing curriculum for Competency Based Education (CBE), an effective and efficient model, Systematic Curriculum and Instructional Development (SCID), has been devised. SCID has five phases: analysis, design, development, implementation, and evaluation. Each of 23 components involves several steps, some optional. Phase 1 may involve needs analysis, job analysis, task verification, and task analysis. In Phase 2, task performance information collected during analysis is used to specify the job skills, knowledge, and attitudes the program will develop in the learner. During this phase, decisions are made regarding the appropriate training settings, entry-level qualifications, and the sequencing of learning objectives. Phase 2 concludes with the preparation of a training plan. Phase 3 results in the production, review, and revision of instructional materials. Implementation (i.e., step 4) involves putting the education or training program into operation. After pretesting, the training is conducted as planned and learner performance is evaluated with progress and posttests. Phase 5 gathers data on the overall instructional process, program outcomes, student follow-up data, worker productivity data, and cost-effectiveness data, to conduct a summative evaluation. Here under, Laird and Stevenson (1993) showed the simplified approach to competency based curriculum development in Australia. Ethiopian competency based curriculum also follows this process.

Figure 1: Simplified approach to competency based curriculum development in Australia by Laird and Stevenson (1993)

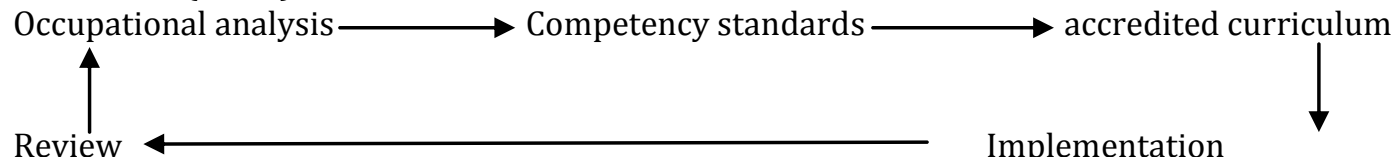

Recognition of prior learning in TVET: Industry indicated a desire to offer recognition of prior learning to identify skill gaps and to avoid unnecessary training through recognition of current skills gained via on-thejob training (Bowman et al., 2003). For instance, in a study conducted by Bowman et.al (2003), students said they applied for recognition of prior learning because they have some work experience and did not want to repeat their training, as well as wanting to fast-track through a qualification, thereby saving time and entering the workforce sooner. Knight (2005) also states that Recognition of Prior Learning (RPL) provides formal recognition for vocational knowledge or skills gained on-the-job or as a result of other informal or unstructured learning experiences. He says that RPL, if granted, can count towards completion of recognized vocational qualifications. O.S.K, Ramdass, and Santokhee (2012) added that RPL is primarily concerned with the type of learning, that is, learning which is achieved outside the mainstream education and training, and it aims to validate and give credit for achievements acquired outside the classroom. A similar trend is being followed in Ethiopian TVET system that students who acquired skills informally outside formal training can take Center of Competence exam and be certified.

\section{Current Reformed Competency Based TVET Curriculum Development Procedures in Ethiopia}

Curriculum Development Process: Modularization: In the European context, modularization is one of the methods of controlling curriculum (structural control mechanism). Thus, the term modularization refers to widely divergent models of opening up courses of study and making them more flexible with respect to organizational, temporal, and content-related structures (cf. FROMMBERGER, 1999, as cited in Rauner and Maclean, 2008). They illustrate that in structuring curricula by way of modularization, the main emphasis is on combining fundamental and supplementary building blocks of education and training and, thus, on their variability and flexibility with reference to temporal and content-related aspects. They give examples from two countries: 
An example of modularized vocational education has been implemented in Great Britain with the system of National Vocational Qualification (NVQ). NVQ provides for the individual compilation of various partial certificates in a 'qualification portfolio' and facilitates access to employment already on the basis of partial certification. In the modularization model used in Denmark and the Netherlands, the degree also functions as the sum of the partial certificates obtained. But these are mandatory components assigned specifically to certain courses of training, and, in this sense, these models are more moderate variants of modularization.

Dereje (2013) also states that modularization provides a means of reorganizing the curriculum to provide increased opportunities for a wider student population. A modular curriculum could provide the chance for students to enroll at the time that most suited their needs. A key feature of modularization is the flexibility it offers, allowing students more choice of subject combinations and wider access to the curriculum. The definition and the application of modularization in Ethiopian TVET have been described as follows in the National Technical \& Vocational Education and Training Strategy (MOE, 2008, p. 29).In this first paragraph, it is discussed how modularization fits the competency approach in TVET. It is stated that TVET programs will be organized in a modular fashion to meet the requirements as defined in the occupational standards. In this way, each module or combination of modules describes an employable set of competences. Successful completion of each training module shall be dependent on assessment and certification in conjunction with the assessment specifications stipulated in the occupational standards. The modularization of TVET is a central mechanism of making TVET delivery flexible and providing for flexible entry and exit points. The second paragraph gives even more additional clear description including how certification is done and its flexibility, as it is done at international context. It illustrates that different TVET modules can be combined into long-term programs representing the entire teaching, training, and learning necessary to achieve an occupational qualification. Through this modularization, a trainee may, for personal reasons, exit a long-term program prematurely while having acquired competencies that would allow her/him to successfully perform certain jobs in the labor market. S/he may re-enter the TVET program at a later stage, continue with the missing modules and thus complete her/his qualification.

It says that individual modules or a number of modules may also be delivered in short programs. In this case, trainees either acquire an important set of competencies (equivalent to a partial qualification) valuable in the labor market and/or achieve the first steps of a potentially longer TVET career that may eventually lead to a comprehensive occupational competence. In the course of their individual career, trainees may attend different TVET modules over time, if necessary by different providers, to finally master a comprehensive competence. Generally, when we compare this description of modularization with European trend, we can observe more similarities such as its flexibility with respect to delivery (trainees can quit training when they finish a module having certified for that level and can continue the next higher level next time), certification (partial certification can be done), and how competencies are organized (structuring as it is described in European sense of modularization).

Description of the participating groups in curriculum development: According to my interview with agency officers (Hulualem, Mosisa, and Fitsum), the direct participants in TVET curriculum development are industry experts who have know-how about each occupation, employers who can serve as main sources of labor demand analysis, regional TVET authorities and TVET providers, and teachers.

Setting occupational standards and competencies and its relationship with curriculum: In this section, the processes of setting occupational standards according to MoE (2011) are summarized. The Occupational Standard serves the function of the national standard that details the occupational requirements in terms of competencies. It describes the competencies that an individual must possess to be able to perform and be productive in the world of work. The competencies are expressed in discrete units of competence that define the particular scope of work resulting in a product, service or decision (MOE, 2011).According to MoE (2011), in the development of the Occupational Standards (OS), representatives of industry experts and practitioners are gathered together to identify the competencies that the expert workers need to possess to be able to perform and be productive in the workplace. Once all these competencies are identified and defined, the OS is packaged and matched with the National TVET Qualification Framework (NTQF). This is to determine the level of qualification as described in the framework. The NTQF illustrates the scope, compositions, and degree of responsibility a qualified person can assume in the workplace. According to MoE the objective of 
TVET delivery is to qualify people according to the occupational requirements by facilitating a learning process geared toward attaining the set of competencies defined in the respective Occupational Standard.

In addition, it stated that translating Occupational Standards into suitable TVET programs is the challenge of TVET delivery. Within this process, curricula as well as training, teaching, and learning materials have to be transformed into an outcome based enabling elements to adequately reflect the expected outcomes as defined in the OS.

Figure 2: A relationship Between Occupational Standard and Curriculum Module Occupational Standard

Curriculum

Module

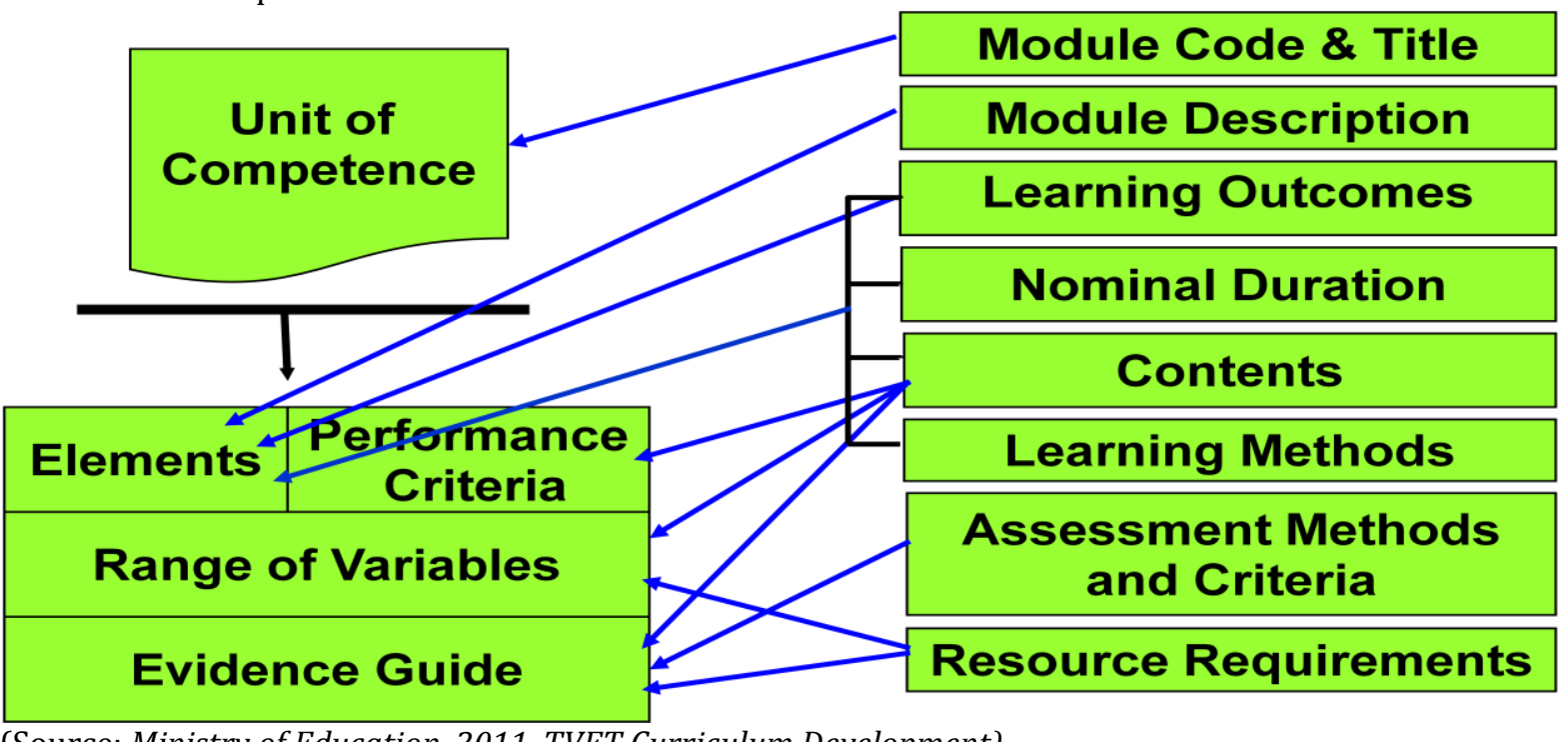

(Source: Ministry of Education, 2011. TVET Curriculum Development)

Occupational standards define the competencies of a worker according to requirements in the labor market. As outlined above, occupational standards comprehensively describe the competence a person has to achieve in order to be considered "qualified" in a certain field. Competence includes the entire range of skills, knowledge, and attitudes necessary to perform a specific job. Occupational standards are developed for all occupational fields at all relevant qualification levels attainable within the TVET system. Each occupational standard can be broken down into units that describe a set of "employable" competencies. Occupational standards are described in the same, nationally approved, format and are publicly available. This enhances transparency about occupational qualifications among employers, trainees, and TVET providers. Responsibility for organizing, facilitating and endorsing occupational standards rests with the Federal TVET Agency. However, as occupational standards reflect the competence requirements of the world of work, stakeholders from the world of work particularly employers are the major actors in the development of the standards, as they are in the developed and emerging countries. The TVET Agency, therefore, forms expert panels for standard setting, comprised mainly of experts with a profound knowledge of workplace requirements.

Appropriate internationally recognized occupational standards are checked for compatibility with the participation of the industry and verified to be in conformity with the national vision. Then it is approved as the National Occupational Standard by the Federal TVET Agency. Consensus is obtained on the modality of identifying the pertinent standard setting from the internationally recognized ones. The Federal TVET Agency prescribes the procedures to be followed for standard setting and publishing them. Occupational standards must be based on the needs of the labor market. Therefore, the identification and clustering of occupations for which occupational standards are developed - are made with reference to the needs of the national labor market demand. A labor market analysis is instrumental in identifying the need for new occupations as well as indicating the need for revision and adaptation of existing national standards once technological and/or economic developments bring about changes to the qualification needs. Identification and clustering of 
occupations are made in close cooperation with the Ministry of Labor and Social Affairs and the Civil Service Agency as well as other concerned bodies to ensure that the TVET occupational standards take into account the defined occupational titles from the National Occupational Classification System. OS should be internationally compatible.

\section{Guiding Principles in Curriculum Development}

MoE (2011) also stated that the development of TVET curriculum is guided by the following principles. These principles standardize not only the development but also the format and content of the curriculum throughout the country -

- Curriculum development is driven by the OS thus needs to start with the systematic analysis of OS.

- Curricula have the character of "enablers" on the delivery level. They aim at providing a systematic and consistent framework, without necessarily being too rigid and detailed.

- Curricula need to reflect the specific context and conditions of occupational learning. Accordingly, the respective relevant aspect of training delivery such as disparate target groups and their characteristics, mode of delivery, regional/local conditions and availability of training resources have to be taken into account.

- It is highly recommendable to follow the principle of modularization when developing TVETCurricula. This means structuring the TVET-Program into a set of related Learning Modules.

- Curricula should reflect learning, then, assessment and progression or practice and reassessment until competent. This means the learning situation presents the learner with work which must be performed and assesses the learner in the performance of that work.

- A different group of developers may come up with different curriculum structure but what is essential is that the outcomes of the training and assessment of the total course are constant with the occupational standard or OS.

- Curricula need to be revised periodically. Since occupations and their specific characteristics change over the time and Occupational Standards will be reviewed and adapted accordingly within the process of OS-revision. Curricula need also to be revised in order to continuously reflect "up to date" occupational requirements.

Organization of TVET Curricula: In this section, the organization of TVET curricula as it is described by MoE (2011) is briefly summarized. It is stated that the basis for TVET Program design is the OS in general and the Unit of Competence in particular. It should not be assumed that one unit of competence will lead to one learning module. The number of learning modules depends on the breadth and depth of the unit of competence. The decision is made after a thorough study of the occupational standard and its units of competence. The learning module or modules (if there are several) of a unit of competence should be selfcontained. It should already contain the contextual (knowledge-based), skills (performance-based) and attitudes (behavioral-based) requirement of the unit of competence.

Figure 3: Organization of Model TVET Curricula

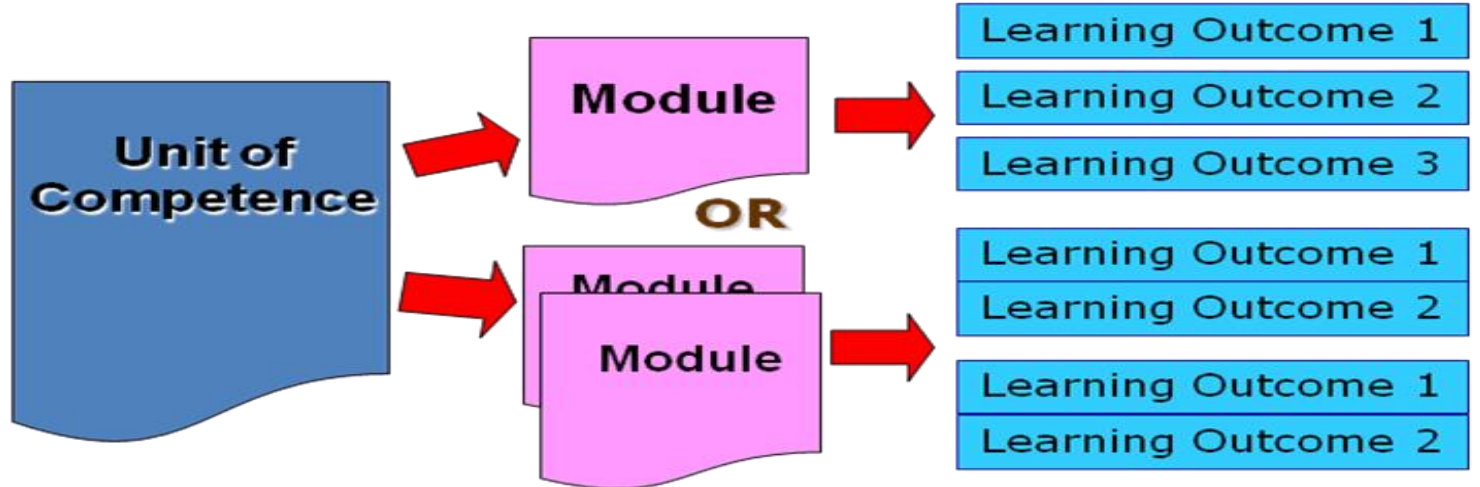

(Source: Ministry of Education, 2011. TVET Curriculum Development) 
Components of TVET Curricula: MoE (2011) also stated that when developing Curriculum within the context of outcome based TVET delivery and the National Ethiopian TVET System, it covers the following two main components - TVET-Program Design and Learning Modules. The TVET-Program design outlines the general overview of the main relevant parameters of the specific TVET Program and how they are generally structured to meet the learning outcomes derived from the OS. Within the context of modularized curricula, Learning Modules are core elements of each TVET Program. They specifically describe how a set of defined occupational competence derived from the Occupational Standard will be adequately addressed in the context of TVET delivery.

\section{A1. TVET Program Design}

It is also stated that the basis for the TVET program design is the combination of Units of Competence from one particular OS. A decision needs to be made about the structuring of these units of competence. The program design needs to consider the following important issues -

- The sequencing of modules should reinforce learning experiences, by building on competencies previously acquired.

- The number of modules should be based on the breadth and depth of each unit of competence.

- As learners progress through the program there may be points at which they could leave with recognized outcomes leading to possible employment opportunities or re-enter the program at a later stage to continue their training. The following are the components of the program

TVET Program Title: gives a clear indication of the main focus of the TVET Program; it corresponds with the Occupational Standard and the National TVET Qualifications Framework (NTQF); and expressed in a function-based title - Example: "Metal Fabrication and Assembly (Level IV)".

TVET Program Description: contains information regarding - what occupation, in what industry sector and field - learners participating in the program will be qualified. Thus, it shows the relevance the TVET Program has for the employment sector. In addition, it should also provide a brief outline covering the main aspects and characteristics of the TVET Program in terms of scope, coverage, and delimitation.

TVET Program Learning Outcomes: They briefly describe the overall intention of the program and the intended results of learning. They reflect the expected performance outcomes as defined in the respective OS. In this sense, learning outcomes are the set of required occupational competencies (units of competence) listed to show the coverage of the program.

Duration of the TVET Program: It is the total length of the TVET Program. The benchmark with regard to duration is the total amount of nominal learning time necessary to cover all the defined program learning modules, institutional assessment (summative evaluation) that will be undertaken by the trainees and the time needed for industry immersion.

Qualification Level and Certification: It explains the corresponding institutional certificate(s) the individual will receive upon satisfying certain internal requirements. TVET program that offers a number of defined entry and exit points have to grant trainees an education based qualification, either nested or laddered certificate of completion or competence,

Target Groups: They define the specific group of individuals that is catered by the program. Target Groups and related frame conditions have a major impact on TVET Program design, affecting all major aspects ranging from duration to concept and mode of delivery. Since the specific frame conditions with regard to disparate target groups can differ substantially, a clear definition of the target groups and sound analysis of related specific frame conditions is, therefore, an important pre-requisite with regard to successful TVETDelivery.

Entry Requirements: They define the pre-requisites of the attendant of the TVET-Program. Recognition of prior learning is an important aspect to be covered. Entry requirements in the sense of pre-requisites for entering a certain TVET Program should be formulated as competencies (which do not necessarily have to be acquired through certain formal types of education and training). Prerequisites such as age, physical condition etc., if necessary should be formulated based on the occupational requirements.

Mode of Delivery: It describes the strategy that will be used in the delivery of the TVET Program. Mode of delivery deals with the issue of appropriate methodological and organizational approach to the learning process. Appropriateness will depend on the context of the unit of competence and program as a whole. 
TVET Program Structure: It provides the overview and outline of the program in terms of contents (modules) and their sequencing (when and how long) in the process of implementation. The practicable way of presenting the contents and sequence is by tabular form. Sequencing structure is the logical progression and scheduling of modules and subjects. Typical considerations with regard to sequencing are from simple to complex; from general to specific; or from easy to difficult. Respective exit and entry points are also indicated. These exit and entry points are indicated after the module have been completed or on the basis of competence acquired

Table 1: A Portion of TVET Program Structure

\begin{tabular}{|c|c|c|c|}
\hline Unit of Competence & Module Code \& Title & Learning Outcomes & $\begin{array}{l}\text { Duration } \\
\text { (In Hrs) }\end{array}$ \\
\hline CON BI01 011110 & CON BI01 M01 0310 & Identify types of drawings & \\
\hline Read and Interpret & Reading and Interpreting & Check changes to drawing & \\
\hline $\begin{array}{l}\text { Plans, Maps, and } \\
\text { Specifications }\end{array}$ & $\begin{array}{l}\text { Plans, Maps, and } \\
\text { Specifications }\end{array}$ & $\begin{array}{l}\text { Locate and identify key features on a } \\
\text { site plan }\end{array}$ & 80 \\
\hline & & Read and interpret job specifications & \\
\hline CON BIO1 021110 & CON BIO1 M02 0310 & Plan and pr & \\
\hline Carry-out & Carrying-out & Perform measurements & \\
\hline Measurements & Measurements & Perform calculations & \\
\hline Calculations & Calculations & Estimate approximate quantities & 40 \\
\hline
\end{tabular}

(Source: Ministry of Education, 2011. TVET Curriculum Development)

Institutional Assessment: It illustrates the methods, arrangement, and scheduling of trainees assessment. It includes answer to the major questions "how?", "when?" and "where?" Applicable assessment modalities and structures are laid down in the Evidence guide of the Unit of Competence of the OS. Moreover, trainee's evaluation should use both - the formative and summative evaluation - to determine the extent to which learning outcomes are achieved. Formative evaluation normally takes place during training while summative evaluation is carried out at the end of a particular period of learning, e.g. Learning Modules.

Trainer's/Facilitator's Profile: It specifies the minimum essential qualification, experience, and competencies as well as specialized qualifications required with a view to implementation of the TVETProgram. It should be in compliance with the Total Quality Management System and respective accreditation criteria.

Resource Requirements: They are the materials, tools and equipment and other facilities essential to the delivery of the TVET Program. It is a complete list of Training- Teaching- and Learning-Materials (TTLM) to support occupational learning processes and thus helping to achieve the desired learning outcomes (LO).Tools and equipment used for learning purposes are also considered as resource requirements. They are defined according to training or learning requirements derived from the Range of Variables of the Occupational Standard (OS)

\section{A2. Learning Module Design}

Reference to TVET-Program: This section should state the title of the TVET Program the learning module was developed for and the unit of competence being addressed.

Module Title: The title chosen for the module will have some influence on how the module is perceived in the training sector. It should convey a clear message of what the module entails. Mostly, the title of the Unit of Competence is adapted as the title of the Module if the correspondence is one to one. The action word or verb in the title of the unit is written in the gerund form (ending in "ing").

Module Code: The module code is an identifier which uniquely identifies a module within a training organization. Each training provider is required to allocate a unique module code to each module in which a learner may enroll. TVET providers are encouraged to adopt the national code key to facilitate comparability of information.

Nominal Duration: In determining the nominal hours it is required to judge the amount of anticipated hours a learner holding the prescribed entry competencies will spend, on average, to achieve the specified learning outcomes including practice to master all the learning outcomes of the module. 
Module Description: Briefly describes the overall intentions of the module with emphasis on learning outcomes. Each module is linked to the standards and made sure to give a clear picture of what the trainee should be able to do after completing the module.

Learning Outcomes: These are clear statements of what the learners are expected to achieve upon completion of the module. A careful examination of the relevant unit of competence -the module is designed from- will ensure that the learning outcomes are appropriate. They are stated in behavioral terms that can be observed and measured. Each learning outcome is described separately beginning with an action word followed by a modifier and object. Generally, the elements of the unit of competence also serve as the learning outcome of the module. Hence it is better to just copy them to serve as the learning outcomes of the learning module.

Module Contents: This section identifies the broad areas of content or underpinning knowledge, skills, and attitudes required to achieve the learning outcomes. Only content which directly relates to the learning outcomes should be added. References have to be made to the Performance Criteria, Critical Aspects of Competence and the Required Knowledge, Attitudes and Skills section within the Units of Competence.

Learning Methods: As part of the Program quality assurance process it is required to provide evidence that the Program has the capacity to offer flexible learning opportunities. The training program has to be based on a mix of flexible training approaches that are structured for outcome based learning. At the program level, decisions can be made about the general modes of delivery for the program as a whole. On the other hand, decisions about learning tactics can be left open to be closely examined at the module level. There may be overall strategies for delivery with variations for certain modules.

Assessment Methods and Criteria: This portion of the learning module lists the methods used to gather evidence of sufficient quantity and quality to make a sound judgment about a learner's competence. These are methods that can be used in assessing the learning outcomes or what have been achieved and what the learners can do after certain learning process. It is stated that, where possible, it is encouraged to use a holistic assessment approach. A holistic approach to competence assessment is one in which competence is seen as the ability to draw in and integrate a variety of knowledge, skills, and attitudes within a realistic work context. There is an extensive range of assessment methods available to obtain evidence necessary to assess learner performance.

Resource Requirements: this section provides details about resources for the delivery of the module. Module specific learning resources, tools, and equipment, as well as consumables, supplies, and materials, are listed here.

Practical Steps in the Development of Outcome Based Curriculum: In this part, general steps followed in outcome based curriculum are briefly described.

Step 1) Analyze the occupational standard and its units of competence

- Review the units of the OS and determine if each unit, when applied in a work situation, can stand alone. If this is the case the unit can be made as one learning module. However, if the unit needs another unit, this can be made a pre-requisite of that unit.

- For those units with elements that are extensive and can be clustered into two or three major activities (complete in itself and have a clear picture of what the learner should be able to do) can be made into two or three modules.

Step 2) Determine the program learning outcomes

- The program learning outcomes are the title of the units of competence of the OS

Step 3) Determine and identify the different module titles

- The unit title with one-to-one correspondence can be used also as module title, just add 'ing' in the action word e.g. conduct becomes conducting.

- For "more modules-to-one unit", the outcome can be used as the title of the module.

Step 4) Accomplish the template for Learning Module

Step 5) Define the qualification level and certification

- This should match the OS and NTQF qualification

Step 6) Describe the target group and their entry requirements

Step 7) Decide on the mode of delivery

Step 8) Design the program structure 
Step 9) Describe the context under which the institutional assessment will take place

Step 10) Define the trainer's / facilitator's profile

Step 11) List, as an annex, the resource requirements of the program using the suggested tabular format.

Step 12) Consolidate the learning modules and package the program

\section{Examination of Ethiopian TVET against the Theory and Practice of Competency Based Curriculum}

As we can see from different kinds of literature we have discussed in the literature review, Ethiopian TVET curriculum development process follows almost similar procedures with different competency based TVET curriculum development processes in another world. However, we can say that it follows the similar process as that of Australia. Because as we can see from figure 1 above, Australian TVET curriculum development starts from occupational analysis while Ethiopia's also starts with occupational analysis. Schokland Program (2012) confirms this similarity while it states that, after adopting best experiences from countries such as Australia and the Philippines, the new TVET strategy has decentralized the preparation of curricular materials to institutions that deliver training. In America, as we can see from DOCUM, it starts from detail labor market analysis. In addition, Candy and Harris (1990) illustrated that from an analysis of the literature (see, for example, Blank, 1982; DEET, 1988; DOLAC, 1988; Hobart and Harris, 1980, OSU, 1986; Thompson, 1985), TVET curriculum features may be summarized as follows: (i) the pre-specification of individual competencies to be attained; (ii) the modularization of the curriculum, with each component building on the cumulative attainment of the preceding modules; (iii) individualization of instruction, so that learners are free to progress at their own rate; and (iv) identification of precise standards of performance to be achieved and demonstrated by learners before progressing. These authors also state that however, notwithstanding criticisms, CBVE has attracted a lot of positive support, and a number of advantages are claimed by its advocates. These include: (i) the existence of public criteria for success by students, which leads to less subjectivity in marking; (ii) because learners 'teach themselves', there is more time for staff to spend with students experiencing difficulties; (iii) the self-paced nature of the approach allows opportunities for higher ability students to undertake extension work; (iv) better use is made of hardware and workshop equipment because of staggered progress; ( $v$ ) the CBVE approach is more motivating than conventional teaching strategies because learners exercise more discretion over pacing, sequence, and mode of learning; and (vi) learning outcomes are more enduring because of the requirement for demonstrated 'mastery' before progressing to more advanced skill levels.

Taking into consideration the practical advantage of competency based TVET curriculum, Ethiopia has been applying it for years. According to my understanding from my readings, the main important problem may limit the competency based TVET curriculum in Ethiopia may be a lack of knowledge and experience to develop a curriculum at the local level in this decentralized responsibility to develop curriculum at TVET institutions level. Regarding this idea, Schokland Program (2012) states that due to lack of both professional and methodological capabilities among the training institutions, the task of preparing curricular materials is yet shouldered by the regional TVET agencies. This practice of support is told to continue until training institutions have the capability or competence to develop appropriate curricula. The preparation of curriculum development guides, model curricula and the like will continue to maintain the required quality of TVET delivery. One can conclude that the decentralization process of curricular materials preparation did not yet address the intended objectives. On the other hand, Schokland Program also identified that in addition to the problem of decentralization, the continuous change made in the required occupational standards is another challenge in the effective implementation of the reformed TVET approach. While training institutions have set themselves and started to provide training in certain occupational standards disseminated, the MoE in the mean time updates and/or replaces those occupational standards with new ones. This has created confusion, resource wastage and grievance among the training institutions, the management, the instructors as well as the students. The preparation of curricular materials is also highly affected by such inconsistencies at the OS level because it requires repeated parallel reworking although the dynamic nature of a curriculum is undeniable. In order to achieve the competencies we drive from occupational standards, we need one and only one thing, which is real practice. To practice the industry and become competent, we need machines. Can we afford it? I had been teaching English at TVET for two years six years ago and what I observed was that the shortage of resources for practice- many students use one computer at the same time and turn by turn, 
students had to go far in summer to learn in practice what they learned in TVET. Learning would be effective of if learning the theory immediately followed by practical learning.

\section{References}

Bowman, K., Clayton, B., Bateman, A., Knight, B., Thomson, P., Hargreaves, J., Blom, K. \& Enders, M. (2003). Recognition of prior learning in the vocational education and training sector. A project for the Australian National Training Authority conducted by the National Centre for Vocational Education Research in conjunction with the University of Ballarat and the Centre Undertaking Research in Vocational Education. Retrieved from https://www.ncver.edu.au/...

Candy, P. C.\& Harris, M. R. (1990). Implementing Competency-Based Vocational Education: A View from Within. Journal of Further and Higher Education, 14(2), 38-58. doi:10.1080/0309877900140203

Chyung, S. Y., Stepich, D.\& Cox, D. (2006). Building a Competency-Based Curriculum Architecture to Educate 21st-Century Business Practitioners. Journal of Education for Business, 81(6), 307-314. doi:10.3200/joeb.81.6.307-314

Dereje, D. (2013). Current practices and prospects of Technical and Vocational Education and Training (TVET): the case of East Wollega Zone. A Thesis (Unpublished)

Knight, B. (2005).Assessment for recognition of prior learning in technical and vocational education and training in Australia: where to from here? National Centre for Vocational Education Research Ltd. Retrieved from http://www. iaea. info/

Laird, D. \& Stevenson, J. A (1993). Curriculum development framework for vocational education. Australian and New Zealand Journal of Vocational Education Research,3,71-92. Retrieved from www.voced.edu.au/content/ngv\%3A31694

Learn4Work Schokland Program. (2012).Technical and Vocational Education and Training Mapping in Ethiopia Final Report. Retrieved from The Edukans Foundation website: http://schoklandtvet.pbworks.com

MacNeil , A.J., Prater, D.L. \& Busch, S. (2009). The effects of school culture and climate on student achievement. International Journal of Leadership in Education: Theory and Practice, 12(1), 73-84, DOI: $10.1080 / 13603120701576241$

Ministry of Education (2008). National Technical \& Vocational Education and Training Strategy.

Ministry of Education (2011). Ethiopian TVET System Model curriculum.

Norton, R.E. (1992). SCID: A Competency-Based Curriculum Development Model. Retrieved from https://www.researchgate.net/publication/234569480_SCID_A_CompetencyBased_Curriculum_Development_Model

O.S.K, K. A., Ramdass, R. \& Santokhee, U.G. (2012). Recognition and Validation of Prior Learning: The Example of Mauritius. Association for the Development of Education in Africa.

Rauner, F. \& Maclean, R. (2008). Handbook of Technical and Vocational Education and Training Research. UNESCO-UNEVOC International Centre for Education. Germany: springer

Soare, E. (2015). Perspectives on designing the competence based curriculum. Social and Behavioral Sciences, $180,972-977$.

Wesselink, R., Groen, A.M., Biemans, H. J. \& Mulder, M. (2010). Using an instrument to analyze competence-based study programs: experiences of teachers in Dutch vocational education and training. Journal of Curriculum Studies, 42(6), 813-829, DOI: 10.1080/0022027100375924 